\title{
Grup veya Bireysel Barındırılmanın Buzağı Büyüme Performansı ve Bazı Davranışlar Üzerine Etkisi
}

\author{
Gökhan GÖKÇE ${ }^{1 *}, \quad$ Serap GÖNCÜ${ }^{1}$
}

\begin{abstract}
Öz
$\mathrm{Bu}$ çalışma buzağıların büyüme performansı ve sosyal davranışları üzerine barındırma sistemlerinin etkilerini araştırmak amacıyla yapılmıştır. Çalışma materyalini 16 baş dişi Siyah Alaca buzağı oluşturmuştur. Bireysel barındırılan buzağılar önünde gezinti alanı (genişlik 136, uzunluk 120, yükseklik $90 \mathrm{~cm}$ ) bulunan fiberglas (genişlik 106, uzunluk 118, yükseklik $140 \mathrm{~cm}$ ) kulübelere, grup olarak barındırılan buzağılar ise $5.88 \mathrm{~m}$ genişlik, $5.20 \mathrm{~m}$ uzunluk ve $1.75 \mathrm{~m}$ yükseklikteki bölmelere yerleştirilmiş̧lerdir. Buzağılların doğum ağırlıkları temel alınarak gruplara rasgele dağıtılmış ve bütün buzağılar doğumu takip eden 3 gün anaları ile bırakılarak kolostrum almaları sağlanmıştır. Daha sonra çiftliğin standart süt içirme programı 10 hafta süreyle uygulanmıştır. Ek olarak deneme boyunca buzağılara buzağı başlangıç yemi, kuru yonca otu ve su serbest olarak verilmiş̧ir. Her buzağ saatlerinde 10 dakika aralıklarla gözlemlenmiştir. Grup olarak barındırma bireysel barındırmaya göre, günlük canlı ağırlık kazancı, buzağı başlangıç yem tüketimi, yonca tüketimi, ayakta durma, yürüme ve oyun oynamayı $(\mathrm{p}<0.05)$ artırmıştır.
\end{abstract}

Anahtar kelimeler: Grup barındırma, bireysel barındırma, davranış, buzağı.

\section{The Effects of Housing Systems on Growth Performance and Behavior of Calves}

\begin{abstract}
This study was conducted to investigate the effects of housing systems on the growth performance and social behavior of the calves. The material of the study was 16 Holstein female calves. The individual group were housed in fiberglass calf hutches (106 width X 118 length X $140 \mathrm{~cm}$ height) with individual paddock (136 width X 120 length X $90 \mathrm{~cm}$ height) for each calves. In the group housing, group of eight calves were housed in group pens (5.88 m width, $5.20 \mathrm{~m}$ length ve $1.75 \mathrm{~m}$ height) with feeding and watering facilities. The calves were randomly distributed in the two groups on the basis of their birth weight. The calves were fed with colostrum for first 3 days before allotting to standard milk feeding schedules of the farm ad libitum calf starter, alfaalfa hay and water were introduced from the first week and was continued till the end of the experiment (10 weeks). Each calf was observed twice a week for 1 hour at 8:00, 11:00, 14:00, 17:00 and 20:00 at 10 minute intervals. The results indicated that, group housing system increased the body weight gain, starter intake and alfalfa hay intake, proportional events of playing, walking and standing $(\mathrm{p}<0.05)$ compared with the individual housing system of calves.
\end{abstract}

Keywords: Group housing, individual housing, behaviour, dairy calf.

ORCID ID (Yazar sırasına göre)

0000-0001-6980-8989, 0000-0002-0360-2763

\footnotetext{
Yayın Kuruluna Geliş Tarihi: 05.05.2020

Kabul Tarihi: 11.06.2020

${ }^{1}$ Çukurova Üniversitesi, Ziraat Fakültesi, Zootekni Bölümü,01330 Adana

*E-posta: ggokce@cu.edu.tr
} 


\section{Grup veya Bireysel Barındırılmanın Buzağı Büyüme Performansı ve Bazı Davranışlar Üzerine Etkisi}

\section{Giriș}

Süt sığırcılı̆̆ı işletmesi için en önemli görevlerden bir tanesi buzağı büyütmedir. Başarılı bir buzağı yetiştirme programının anahtar faktörü ise buzağı yetiştirme periyodu boyunca stres oluşturacak koşullardan kaçınılmasıdır. Bir buzağı için sütten kesim sonrası bireysel bölmelerden grup bölmelerine geçiş en önemli değişimdir. Buzağı kulübeleri sütten kesim öncesi buzağıların gelişimi ve sağllğ 1 için en efektif amenajman pratiklerinden biri olup dünyada çok uzun yıllardır başarılı bir șekilde kullanılmaktadır. Grup barındırma buzağılara daha fazla sosyal iletişim kurma imkânı sağlar. Ancak burada barındırılan buzağıların bakımları zordur ve hastalık bulaşma riski daha fazladır. Ayrıca grup barındırılan buzağıların her birinin sağlık ve refahının sağlanması için gerekli işçilik artmaktadır. Buzağılar sürü hayvanlarıdır, normal sosyal gelişimleri ve davranışları için mutlak grup halinde barındırılmalıdırlar. Süt sığırcılığı işletmelerinin çoğunda rutin olarak yeni doğan buzağılar 24 saat sonunda annelerinden ayrilırlar (Rushen ve ark., 2010; Costa ve ark., 2016). Bu genç buzağılar bireysel bölmelere alınarak canlı ağırlıklarının belli bir oranındaki sütü günde iki ögün halinde kovalardan alırlar. Yakın zamanda yapılan araştırmalar buzağı yetiştirme pratiklerindeki ufak değişikliklerin buzağıların büyüme ve sağlıklarını geliştirici yönde etkileri olduğunu göstermiş̧tir (Phipps ve ark., 2018; Ježek ve ark., 2019). Grup barındırılan buzağılarda erken görülen sosyal etkileşim bu hayvanların ileriki yillarda normal sosyal tepkiler vermelerini sağlamaktadır (Price ve Wallach, 1990; Bøe ve ark., 2003). Bu yararlarına rağmen hala birçok yetiştirici buzağıları düşük hastalık riski, yüksek canlı ağırlık kazancı ve bazı kötü alışkanlıklardaki (diğer buzağıyı emme v.b.) azalmadan dolayı bireysel bölmelerde yetiştirmeye devam etmektedir (Gulliksen ve ark., 2009; Cobb ve ark., 2014).

Çiftlik hayvanlarında hayvan refahının sağlanması önemlidir. Ancak bu şekilde türe özgü davranışlarını sergilenmesi ve yine türe özgü büyüme performansının sağlanması mümkün olabilecektir. Bu ortamın hayvanlara sağlanması onların bir bakıma sağlıklı olmalarına da neden olacaktır. Buna örnek olarak, sıkışık barınmayan, yem için kavga etmeyen bir şekilde barındırılma gösterilebilir. Hayvan refahı, insan refahı ve çevrenin refahı bazı noktalarda çakışabilmekte, ancak gerçek ilerleme bu bileşenlerin çakıştığ gerçekleşmektedir (Sejian ve ark., 2011). Bu bağlamda çalışmanın amacı süt sığırı işletmelerinde yetiştirilen buzağıların farklı barındırma koşullarında (grup ve bireysel barındırma) büyüme performansları ve refahlarına ilişkin davranışlarından bazılarının (ayakta durma, yatma, vücut bakımı, yürüme, obje yalama ve oyun oynama) incelenmesidir.

\section{Materyal ve Yöntem}

Hayvan materyali Çukurova Üniversitesi Ziraat Fakültesi Araştırma ve Uygulama Çiftliği Süt Sığgrccllığı İşletmesinde doğan 16 baş Siyah Alaca dişi buzağidan oluşmuştur. $\mathrm{Bu}$ buzağılardan 8 başı bireysel bölmelerde diğer 8 baş1 grup bölmesine alınmıştır. Bireysel barındırılan buzağılar önünde gezinti alanı (genişlik $136 \mathrm{~cm}$, uzunluk $120 \mathrm{~cm}$, yükseklik 90 $\mathrm{cm}$ ) bulunan fiberglas (genişlik $106 \mathrm{~cm}$, uzunluk $118 \mathrm{~cm}$, yükseklik $140 \mathrm{~cm}$ ) bölmelere yerleştirilmişlerdir (Şekil 1.).
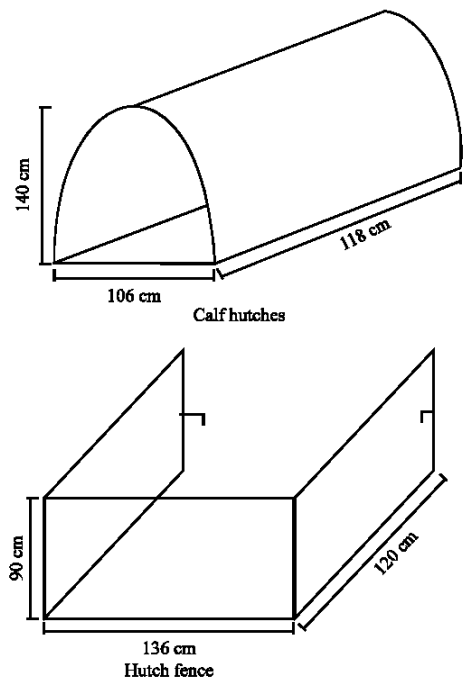

Şekil 1. Buzağ 1 kulübesi ve gezinti alanı ölçüleri. 


\section{Grup veya Bireysel Barındırılmanın Buzağı Büyüme Performansı ve Bazı Davranışlar Üzerine Etkisi}

Grup olarak barındırılan buzağılar ise $5.88 \mathrm{~m}$ genişlik, $5.20 \mathrm{~m}$ uzunluk ve $1.75 \mathrm{~m}$ yükseklikteki bölmelere yerleştirilmişlerdir. (Şekil 2.).

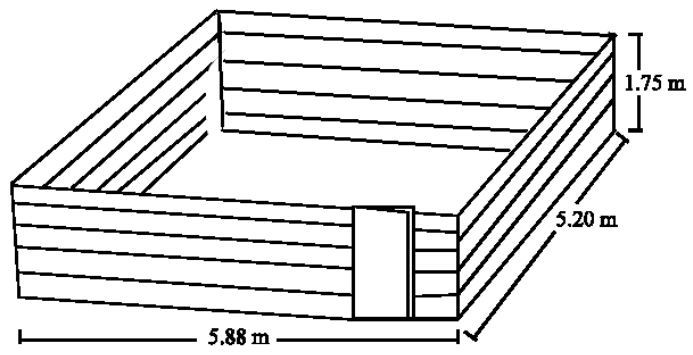

Şekil 2. Grup olarak barındırılan buzağılara ait bölmenin ölçüleri.

Buzağıların doğum ağırlıkları temel alınarak gruplara rasgele dağıtılmış ve bütün buzağılar doğumu takip eden 3 gün anaları ile birakılarak kolostrum almaları sağlanmıştır. Daha sonra canlı ağırlıklarının \% 10'u kadar süt günde iki defa kovalardan verilecek şekilde bir süt içirme programı 10 hafta süreyle uygulanmıştır. Ek olarak deneme boyunca buzağılara buzağı başlangıç yemi, kuru yonca otu ve su serbest olarak verilmiştir. Buzağıların doğum ağırlıkları ve her iki haftada bir canlı ağırlıkları bireysel olarak tespit edilmiştir.

Her buzağ 1 haftada iki kez 1 saat süreyle, saat $08.00,11.00,14.00,17.00$ ve 20.00 saatlerinde, 10 dakikalık aralıklarla gözlemlenmiştir. Toplamda dört gözlemci buzağı aktivitelerini gözlemlemiştir (iki gözlemci bireysel bölmelerde, diğer iki gözlemci grup bölmesini). Buzağıların davranışsal aktiviteleri, rahatsız etmeden 3-4 m mesafeden kaydedilmiștir. Gözlemciler saat başı buzağılara ilk baktıkları andaki görülen aktivitesini davranış gözlem formuna işaretlemiştir.
Çizelge 1. Davranış gözlem formu.

\begin{tabular}{|l|l|l|l|l|l|l|}
\hline $\begin{array}{l}\text { Buzağ } 1 \\
\text { Zaman }\end{array}$ & $8: 00$ & $8: 10$ & $8: 20$ & $8: 30$ & $8: 40$ & $8: 50$ \\
\hline \multicolumn{7}{|c|}{ Davranışlar } \\
\hline & AD & Y & YR & O & OY & VB \\
\hline 1 & & & & & & \\
\hline 2 & & & & & & \\
\hline 3 & & & & & & \\
\hline 4 & & & & & & \\
\hline 5 & & & & & & \\
\hline 6 & & & & & & \\
\hline 7 & & & & & & \\
\hline 8 & & & & & & \\
\hline
\end{tabular}

Gözlemlenen davranışsal aktiviteler ayakta durma, yatma, vücut bakımı, yürüme, obje yalama ve oyun oynamadir.

Çizelge 2. Kaydedilen davranışlar.

\begin{tabular}{|l|l|}
\hline Davranış & \\
\hline AD & Hiçbir şey yapmadan ayakta dikilme \\
\hline Y & Hareketsiz uzanma \\
\hline YR & Bölme içinde yürüme \\
\hline O & $\begin{array}{l}\text { Atlama, zıplama, tekme atma, kendi } \\
\text { etrafında dönme }\end{array}$ \\
\hline OY & $\begin{array}{l}\text { Bölme demirleri, yemlik ve suluk } \\
\text { kovalarını, bölme parçalarını yalama }\end{array}$ \\
\hline VB & Dili ile vücudunu yalama \\
\hline
\end{tabular}

AD: Ayakta durma; Y: yatma; O: oyun oynama; OY: obje yalama; VB: vücut bakımı

\section{Verilerin Analizi}

Davranış gözlemleri zaman örneklemesi (Fraser ve Broom, 1990) yöntemi ile yapılmıştır. Çizelge 1'de deneme için hazırlanan davranış kartı verilmiştir.

Çalışmada elde edilen verilerin analizi, SPSS 10.00 (SPSS Inc., Chicago, 1999) paket programı ile tekrarlanan ölçümlü deneme modeli kullanılarak yapılmıştır. Bu model, aynı birey üzerinde belli bir zaman süreci içinde, bağımsız değişkenler için birçok kez ölçüm alınması durumunda söz konusudur (Göncü, 2000).

\section{Bulgular ve Tartışma}

Çalışmada değerlendirilen büyüme performansları ve yem tüketim değerleri Çizelge 3'de verilmiştir. 


\section{Grup veya Bireysel Barındırılmanın Buzağı Büyüme Performansı ve Bazı Davranışlar Üzerine Etkisi}

Çizelge 3. Barındırma şekillerine göre buzağıların büyüme ve yem tüketim performanslar1.

\begin{tabular}{|c|l|l|c|c|}
\hline Par. & B.Ş. & $\mathbf{N}$ & Ort. & p \\
\hline \multirow{2}{*}{ DA } & G.B. & 8 & $35.16 \pm 0.78$ & \multirow{2}{*}{0.28} \\
\cline { 2 - 5 } & B.B. & 8 & $35.58 \pm 0.75$ & \\
\hline \multirow{2}{*}{ SKA } & G.B. & 8 & $68.4 \pm 0.4515$ & \multirow{2}{*}{0.057} \\
\cline { 2 - 4 } & B.B. & 8 & $67.0 \pm 0.4617$ & \\
\hline \multirow{2}{*}{ GCAK } & G.B. & 8 & $0.47 \pm 0.0062$ & \multirow{2}{*}{$0.024^{* *}$} \\
\cline { 2 - 4 } & B.B. & 8 & $0.44 \pm 0.0078$ & \\
\hline \multirow{2}{*}{ BBYT } & G.B. & 8 & $0.53 \pm 0.0052$ & \multirow{2}{*}{$0.001^{*}$} \\
\cline { 2 - 4 } & B.B. & 8 & $0.50 \pm 0.0059$ & \\
\hline \multirow{2}{*}{ YT } & G.B. & 8 & $0.33 \pm 0.0059$ & \multirow{2}{*}{$0.001^{*}$} \\
\cline { 2 - 4 } & B.B. & 8 & $0.30 \pm 0.0069$ & \\
\hline \multirow{2}{*}{ p<0.01; } & p<0.05 & \multicolumn{1}{|c}{} \\
\hline
\end{tabular}

${ }^{*} \mathrm{p}<0.01 ; * * \mathrm{p}<0.05$

Par: parametreler; B.Ş.: barındırma şekli; G.B.: grup barındırma; B.B.: bireysel barındırma; DA: doğum ağırlığı; SKA: sütten kesim ağırlığı; GCAK: günlük canlı ağırlık kazancı; BBYT: buzağı başlangıç yemi tüketimi; YT: yonca tüketimi.

Çizelge 3 incelendiğinde sütten kesim ağırlığı, günlük canlı ağırlık kazancı, buzağı büyütme yemi tüketimi ve yonca tüketiminin grup barındırılan buzağılarda daha fazla olduğu tespit edilmiştir. Bu çalışma ile benzer şekilde Tapk1 (2007), Babu ve ark. (2004) ile Phillips (2004) grup olarak barındırılan buzağılarda sütten kesim ağırlığını, buzağı başlangıç yemi tüketimini ve yonca tüketiminin daha yüksek olduğunu tespit etmiştir. Pempek ve ark., (2016) günlük canlı ağırlık kazancının grup barındırılan buzağılarda daha fazla olduğunu bildirmiștir. Ancak Tapk1 ve ark.(2006) yaptıkları çalışmada grup barındırmada günlük canlı ağırlı artışları arasında bir fark olmadığını bildirmișlerdir. Yine benzer bir șekilde Yanar ve ark. (2000) bireysel ve grup barındırılan buzağılarda sütten kesime kadar canlı ağırlık kazancında istatistiki olarak önemli bir fark olmadığını tespit etmişlerdir.

Diğer yandan Vieria ve ark. (2010) ise grup ya da bireysel barındırmanın buzağıların büyüme performansını etkilemediğini ileri sürmüştür. Çalışmada değerlendirilen davranıș parametrelerine ait analiz değerleri Çizelge 4'de verilmiştir.
Çizelge 4. Bireysel ve grup barındırılan buzağıların davranışlarına ait gözlem değerleri (\%).

\begin{tabular}{|c|c|c|c|}
\hline $\begin{array}{c}\text { Davranış } \\
\mathbf{\%}\end{array}$ & Bireysel & Grup & $\mathbf{p}$ \\
\hline $\begin{array}{c}\text { Ayakta } \\
\text { Durma }\end{array}$ & 34 & 45 & $0.000^{*}$ \\
\hline Yatma & 42 & 24 & $0.014^{*}$ \\
\hline $\begin{array}{c}\text { Vücut } \\
\text { Bakım1 }\end{array}$ & 8 & 7 & $0.032 * *$ \\
\hline Yürüme & 4 & 18 & $0.000^{*}$ \\
\hline $\begin{array}{c}\text { Obje } \\
\text { Yalama }\end{array}$ & 7 & 4 & 0.084 \\
\hline $\begin{array}{c}\text { Oyun } \\
\text { Oynama }\end{array}$ & 5 & 12 & $0.000^{*}$ \\
$* p<0.01 ; * * p<0.05$ &
\end{tabular}

Grup olarak barındırmada buzağıların daha fazla oynama (\% 12'ye karş111k \%5) ve yürüme (\%18'e karş1lık \%4) eğilimi gösterdikleri görülmüştür. $\mathrm{Bu}$ artan oynama ve yürüyüş aktiviteleri, muhtemelen daha iyi refah durumu belirtisidir. Jensen ve ark. (1998) ve Lawrence (1987), oyun davranışının buzağılarda iyi refahı göstermek için kullanılabileceğini belirtmişlerdir.

Bireysel barındırılan buză̆ıların yatma davranışları, grup barındırılan buzăğlardan (\%42’ye karş1lik \%24) daha yüksek bulunmuștur. Bireysel kulübede barındırılan buzağıların diğer bazı sosyal davranışları sergileyebilmeleri için gerekli alan çok az olduğundan yatma eğilimine girdikleri ifade edilebilir.

Obje yalama bireysel barındırılan buzağılarda (\%7'ye karşı1lık \%4) daha yüksek bulunmuştur. Bireysel kulübelerde barındırılan buzağıların kisitlı alan ve sosyal partnerlerinin olmaması bu tip davranışları artırabilmektedir. Nitekim, Lawrence (1987) bireysel kulübelerde sosyalleşme firsat azalmasının buzağılarda oynama aktivitesini azalttığını bildirmiştir.

Vücut bakımı davranıșı grup olarak barındırılan buzağılarda azalmıştır (\%8'e karşılık \%7). Grup barındırılan buzağılarda diğer buzağıları yalama davranışlarında gözlemlenmektedir. $\mathrm{Bu}$ davranış kendi vücut bakımı davranışında bir azalmaya neden olmuş şeklinde izah edilebilir. Grup olarak barındırma buzağıların sosyal davranışlarını arttırarak daha iyi bir büyüme ve refah sağlamaya yardımcı olabilir. Andrighetto 


\section{Grup veya Bireysel Barındırılmanın Buzağı Büyüme Performansı ve Bazı Davranışlar Üzerine Etkisi}

ve ark., (1998) yaptıkları çalıșmada grup barındırılan buzağılarda, bireysel barındırılan buzağılara göre daha rahat dinlenme pozisyonları alma ve daha fazla sosyal davranış sergileme tespit etmişlerdir.

Nitekim grup olarak barındırmada tespit edilen yüksek seviyede oyun, yürüyüş ve daha fazla sosyal atmosfer buzağıların iştahını artırarak büyüme performans1 üzerine olumlu etki gösterdiği söylenebilir. Ayrıca Chua ve ark. (2002) grup barındırılan buzağıların yem için bireysel kulübelerde barındırılanlara oranla daha fazla zaman harcadığını bildirmişlerdir.

\section{Sonuç}

Bireysel kulübe ile karşılaştırıldığında grup olarak barındırma sistemi sosyal davranış ve büyüme performansı açısından daha uygun görünmektedir. Grup barındırılan buzağılar, bireysel kulübelerdeki buzağılara göre daha fazla oynama ve yürüme aktivitesi ile daha yüksek yem alımı ve günlük canlı ağırlık kazancı sağlamışlardır.

\section{Kaynaklar}

Andrighetto, I., Gottard, F., Andreoli, D., Cozzi, G. (1999) Effect of type of housing on veal calf growth performance, behaviour and meat quality. Livest. Prod. Sci., 57: 137-145.

Babu, L.K., Pandey, H.N., Sahoo, A. (2004) Effect of individual versus group rearing on ethological and physiological responses of crossbred calves. Applied Animal Behaviour Science, 87, 177-191.

Bøe, K.E., Færevik, G. (2003) Grouping and social preferences in calves, heifers and cows. Appl Anim Behav Sci. 2003;80(3):175-90.

Chua, B., Coenen, E., van Delen, J., Weary, D.M. (2002) Effects of paired versus individual housing on the behaviour and performance of dairy calves. Journal of Dairy Science, 85, 360-364.

Cobb, C.J., Obeidat, B.S., Sellers, M.D., Pepper-Yowell, A.R., Ballou, M.A. (2014) Group Housing of Holstein Calves in a Poor Indoor Environment Increases Respiratory Disease but Does Not Influence Performance or Leukocyte
Responses. Journal of Dairy Science 97: 3099-3109.

Costa , J.H.C., von Keyserlingk , M.A.G., Weary, D.M. (2016) Invited review: Effects of group housing of dairy calves on behavior, cognition, performance, and health. Volume 99, Issue 4, Pages 24532467.

Fraser, A.F., Broom, D.M. (1990). Describing, recording and measuring behaviour. In: Farm Animal Behaviour and Welfare (3rd edn). (pp. 7 16). London; ELBS.

Göncü, S. (2000) Adaña Entansif Süt Sı ğırc1lığ1 İşletmelerinde Yetiştirilen Saf Ve Melez Siyah Alaca İnek Sütlerinde Somatik Hücre Sayısına Etki Eden Faktörler Ve Mastitis İle İlişskisi. Ç.Ü. Doktora Tezi, Adana. $128 \mathrm{~s}$.

Gulliksen, S. M., Lie, K.I., Løken, T., Østerås, O. (2009) Calf mortality in Norwegian dairy herds. J. Dairy Sci. 92(6):27822795.

Jensen, M.B., Vestergaard, K.S., Krohn, C.C. (1998) Play behaviour in dairy calves kept in pens: the effect of social contact and space allowance. Applied Animal Behaviour Science, 56, 97 -108.

Ježek J., Petra, G., Barbara, B., Martına, K., Marija, N., Jakob, H.J., Jože, S. (2019) Management Practices Affecting Calves Welfare on Farms in Slovenia. Acta Universitatis Agriculturae et Silviculturae Mendelianae Brunensis, 67(5): 11471152.

Lawrence, A. (1987) Consumer demand theory and the assessment of animal welfare. Animal Behaviour, 35, 293-295.

Pempek, J.A., Eastridge, M.L., Swartzwelder, S.S., K.M.Daniels. (2016) Housing system may affect behavior and growth performance of Jersey heifer calves. Journal of Dairy Science Volume 99, Issue 1, January 2016, Pages 569-578.

Phillips, C.J.C. (2004) The effects of forage provision and group size on the behaviour of calves. Journal of Dairy Science, 87, 1380-1388.

Phipps, A., Beggs, D., Murray, A., Mansell, P. and Pyman, M. (2018) A survey of northern Victorian dairy farmers to 


\section{Grup veya Bireysel Barındırılmanın Buzağı Büyüme Performansı ve Bazı Davranışlar Üzerine Etkisi}

investigate dairy calf management: calfrearing practices. Aust Vet J, 96: 107110. doi:10.1111/avj.12686.

Price E.O., Wallach S.J.R. (1990) Physical isolation of hand-reared Hereford bulls increases their aggressiveness toward humans. Appl Anim Behav Sci. 1990;27(3):263-7.

Rushen, J., de. Passillé, A.M., von Keyserlingk, M.A.G., Weary, D.M. (2010) The Welfare of Cattle. C. Phillips, ed. Springer Publishing. Dordrecht, The Netherlands.

Sejian V, Lakritz J, Ezeji, T, Lal, R. (2011) Assessment methods and indicators of animal welfare. Asian Journal of Animal and Veterinary Advances, 2011; 6(4):301-315.

SPSS Inc. (1999) SPSSfor Windows. Version 10.00, Chicago.

Tapk1, İ., Ustaoğlu, A., Özkaya, S., Okyay, S.M. (2006) Bölme Büyüklüğünün Grup Olarak Barındirılan Siyah Alaca Buzağılarda Gelişim Performansı Üzerine Etkileri. MKU Ziraat Fakültesi Dergisi 11 (1-2): 1-6, 2006.

Tapk1, İ. (2007) Effects of individual or combined housing systems on behavioural and growth responses of dairy calves. Acta Agriculturae Scand Section A, 2007; 57;55-60.

Vieria ,A., von Keyserlingk , M. A. G., Weary, D.M. (2010) Effects of pair versus single housing on performance and behavior of dairy calves before and after weaning from milk. J. Dairy Sci. 93 :3079-3085.

Yanar, M., Yuksel S., Zulkadir , U. (2000) Effects of Individual and Group Housing System on the Growth Characteristics of Brown Swiss Calves Fed Milk Replacer. Pakistan Journal of Biological Sciences, 3: 372-373. 